\title{
Flora da Bahia: Clethraceae
}

\author{
Ricardo de Oliveira Perdiz ${ }^{1,2,3^{*}}$, Ana Maria Giulietti ${ }^{1,4, a} \&$ Reyjane Patrícia de Oliveira ${ }^{1, b}$ \\ ${ }^{1}$ Programa de Pós-Graduação em Botânica, Departamento de Ciências Biológicas, Universidade Estadual de \\ Feira de Santana, Bahia, Brasil. \\ 2 Programa de Pós-Graduação em Botânica, Instituto Nacional de Pesquisas da Amazônia, Amazonas, Brasil \\ ${ }^{3}$ Centro de Estudos Integrados da Biodiversidade Amazônica, Programa de Pesquisas em Biodiversidade, Núcleo \\ Regional Roraima, UFRR/PRONAT, Campus Paricarana, Roraima, Brasil. \\ ${ }^{4}$ Royal Botanic Gardens, Kew, Richmond, Reino Unido.
}

\begin{abstract}
Resumo - É apresentado o levantamento florístico de Clethraceae para o estado da Bahia, Brasil. Uma espécie foi reconhecida, Clethra scabra. São apresentados descrição dos táxons, ilustrações e comentários gerais sobre a espécie.

Palavras-chave adicionais: Brasil, Clethra, florística, Nordeste brasileiro, taxonomia.
\end{abstract}

\begin{abstract}
Flora of Bahia: Clethraceae) - The floristic account of the Clethraceae from Bahia State, Brazil, is presented. One species, Clethra scabra, was recognized. Description of taxa, illustrations and general notes on the species are presented.

Additional key words: Brazil, Clethra, floristics, Northeastern Brazil, taxonomy.
\end{abstract}

\section{Clethraceae}

Árvores ou arbustos. Folhas simples, alternas, sem estípulas, pecioladas, margens inteiras ou, geralmente, serradas, glabras ou pubescentes. Inflorescências em racemos, axilares e terminais; brácteas caducas; pedicelos articulados. Flores bissexuadas, diclamídeas, actinomorfas; cálice gamossépalo, 5(6)-lobado, prefloração imbricada ou quincuncial; corola dialipétala ou com pétalas conatas na base, 5-mera, prefloração imbricada ou convoluta; estames 10(12), livres entre si, obdiplostêmones; anteras rimosas ou poricidas, extrorsas e inflexas no botão floral, introrsas na antese; disco nectarífero ausente; ovário súpero, 3carpelar, 3-5-locular, placentação axilar, óvulos 1 (Purdiaea) ou numerosos (Clethra). Fruto cápsula (Clethra) ou diclésio (Purdiaea); sementes 1 a numerosas, achatadas e aladas; embrião reto, cilíndrico, endosperma carnoso.

Clethraceae está subordinada à ordem Ericales (APG III 2009), abrangendo os gêneros Clethra L. e Purdiaea Planch. e cerca de 95 espécies (Schneider \& Bayer 2004). Distribui-se na região neotropical, sudeste dos Estados Unidos, leste da Ásia e Ilha da Madeira (Fior et al. 2003). A família é representada no Brasil por duas espécies do gênero Clethra; uma delas ocorre no estado da Bahia (Guimarães et al. 2015).

\section{Clethra L.}

Árvores ou arbustos com indumento de tricomas simples, fasciculados ou estrelados; ápice dos ramos

\footnotetext{
*Autor para correspondência: ricoperdiz@gmail.com;

aanagiulietti@hotmail.com; b rpatricia@uefs.br

Editor responsável: Luciano Paganucci de Queiroz

Submetido: 1 fev. 2014; aceito: 4 jun. 2015

Publicação eletrônica: 8 jun. 2015; versão final: 9 jun. 2015
}

congestos de folhas e inflorescência. Folhas com margens inteiras a serradas. Inflorescências em racemos, simples ou agrupados de forma fasciculada, em panículas ou umbelas. Flores actinomorfas, cálice 5-lobado, lobos de tamanho semelhante, prefloração quincuncial; estames 10(12) em dois verticilos, livres ou com filetes adnatos à base das pétalas; anteras 2tecas, sagitadas, introrsas na antese, poricidas; ovário 3-locular, estiletes 3, unidos, ápice curtamente 3lobado ou profundamente 3-partido, glabro ou raramente piloso. Fruto cápsula loculicida, 3-valvar. Sementes numerosas, frequentemente aladas; embrião curto.

Clethra possui cerca de 85 espécies (Schneider \& Bayer 2004) e apresenta elevada diversidade em áreas montanas (Gustafsson 2004). Possui dois centros principais de distribuição, um no leste da Ásia e outro na região neotropical. Duas espécies ocorrem no sudeste dos Estados Unidos e uma espécie é endêmica da Ilha da Madeira. Esse padrão de disjunção é raro, conhecido em poucos grupos de plantas, como no gênero Persea Mill. (Lauraceae) (Schneider \& Bayer 2004).

Clethra caracteriza-se por apresentar folhas simples, agrupadas no ápice dos ramos, com margens inteiras a serradas, indumento tomentoso e estrelado, alvacento, cinéreo ou ferrugíneo, brácteas caducas, flores pentâmeras com ovário súpero, estigma 3lobado e fruto do tipo cápsula loculicida, 3-valvar. Para o Brasil, são referidas duas espécies, Clethra uleana Sleumer, documentada apenas na Região Sul, e C. scabra Pers., com três variedades (Sleumer 1967). Clethra scabra var. laevigata (Meisn.) Sleumer e C. scabra var. scabra são indicadas para a Bahia, chegando até a Região Sul, enquanto C. scabra var. venosa (Meisn.) Sleumer ocorre no Rio de Janeiro, em São Paulo e na Região Sul (Guimarães et al. 2015). 
1.1. Clethra scabra Pers., Syn. 1: 483. 1805.

Figuras 1 e 2.

Árvores ou arbustos $1,5-20 \mathrm{~m}$ alt. Folhas agrupadas no ápice dos ramos; pecíolo $0,7-1,2 \mathrm{~cm}$ compr.; lâmina 5,4-13,4 × 1,9-6,0 cm, obovada a espatulada, base aguda, às vezes assimétrica, ápice arredondado, acuminado ou emarginado, margem inteira, às vezes com dentes esparsos no terço superior, papirácea a coriácea, face adaxial glabrescente, face abaxial com indumento tomentoso e estrelado de coloração alvacenta, cinérea ou ferrugínea, venação broquidódroma a semicraspedódroma, nervuras castanhas, proeminentes na face abaxial. Racemos axilares e terminais, $12,3-18,7 \mathrm{~cm}$ compr.; brácteas lineares, 3-5 $\mathrm{mm}$ compr.; pedicelo ca. $5 \mathrm{~mm}$ compr. Flores com lobos do cálice ovados, externamente tomentosos; pétalas 2-3 $\times$ 4-7 $\mathrm{mm}$, obovadas, côncavas, ápice emarginado ou fimbriado; estames 10 , inclusos; ovário tomentoso, verde, estigma curtamente 3-lobado, alvo-amarelado. Cápsulas 3-6 mm diâm., 3lobadas, tomentosas. Sementes 1-1,5 $\mathrm{mm}$ diâm., ovadas a arredondadas.

Clethra scabra ocorre na Argentina, Brasil, Bolívia, Equador e Peru (Rossi 1992). No Brasil, ocorre na Bahia e em todos os estados das Regiões Sul e Sudeste (Ichaso \& Guimarães 1975; Guimarães et al. 2015). E6, E8, F6, F8, H8, I8: domínios da Caatinga (em florestas de altitude na Chapada Diamantina) e da Mata Atlântica (em florestas ombrófilas densas, de terras baixas ou submontana). Floresce principalmente de novembro a março e frutifica de outubro a abril.

Material selecionado - Abaíra, Serra dos Frios, 1320'S, 41 ${ }^{\circ} 53^{\prime}$ 'W, 1700-1800 m s.n.m., 11 nov. 1993 (fl.), W. Ganev 2459 (HUEFS); Amargosa, Serra do Timbó, Duas Barras, mata do

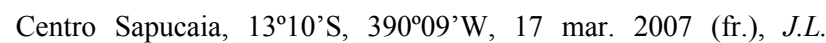
Paixão et al. 1090 (HUEFS); Andaraí, em direção ao Vale do Paty,

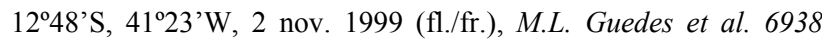
(ALCB, CEPEC); Arataca, Serra das Lontras, 1512'10”S, 39²4'29”'W, 31 mar. 2006 (fr.), J.L. Paixão et al. 955 (CEPEC); Barra da Estiva, face norte da Serra do Ouro, $7 \mathrm{~km}$ do sul da Barra do Estiva, na estrada de Ituaçu, $13^{\circ} 40^{\prime} \mathrm{S}, 41^{\circ} 20^{\prime} \mathrm{W}, 1150 \mathrm{~m}$ s.n.m., 30 jan. 1974 (fr.), R. Harley 15686 (CEPEC); Camacan, RPPN Serra Bonita, 15²3'30”S, 39³3'55”W, 835 m s.n.m., 22 jan. 2007 (fl.), R.A.X. Borges et al. 661 (CEPEC); Ituberá, Fazendas Reunidas Vale do Juliana, 1340'20”S, 3907'04”W, 7 fev. 2004 (f1.), J.G. Carvalho-Sobrinho et al. 189 (HUEFS); Lençóis, Serra da Chapadinha, 12²7'02"S, 4127'03”W, 920 m s.n.m., 23 fev. 1995 (fl.), E. Melo et al. 1723 (ALCB, CEPEC, HRB, HUEFS); Mucugê,,

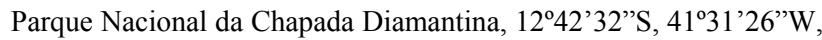
1500-1700 m s.n.m., 17 abr. 2005 (fr.), A.A. Conceição et al. 1316 (HUEFS); Palmeiras, Serra dos Brejões, $12^{\circ} 34^{\prime}$ 'S, $41^{\circ} 23^{\prime} \mathrm{W}, 21$ jan. 2002 (fl.), E.C. Smidt 215 (HUEFS); Piatã, Chapada Diamantina, 1314'43”'S, 4145'28”W, 24 mar. 2005 (fl., fr.), M.L. Guedes et al. 11464 (ALCB); Porto Seguro, Reserva Biológica do Pau-Brasil, 17 $\mathrm{km}$ a oeste de Porto Seguro na estrada para Eunápolis, 16 24 'S, $39^{\circ} 11^{\prime}$ W, 20 jan. 1977 (fl./fr.), R. Harley 18115 (CEPEC); Rio de Contas, mata da base do Pico do Itoibira, $13^{\circ} 34^{\prime} 44^{\prime \prime}$ S, $41^{\circ} 48^{\prime} 41^{\prime \prime} \mathrm{W}$, 10 fev. 1999 (fl.), F.H.F. Nascimento 123 (CEPEC, HUEFS); Rio

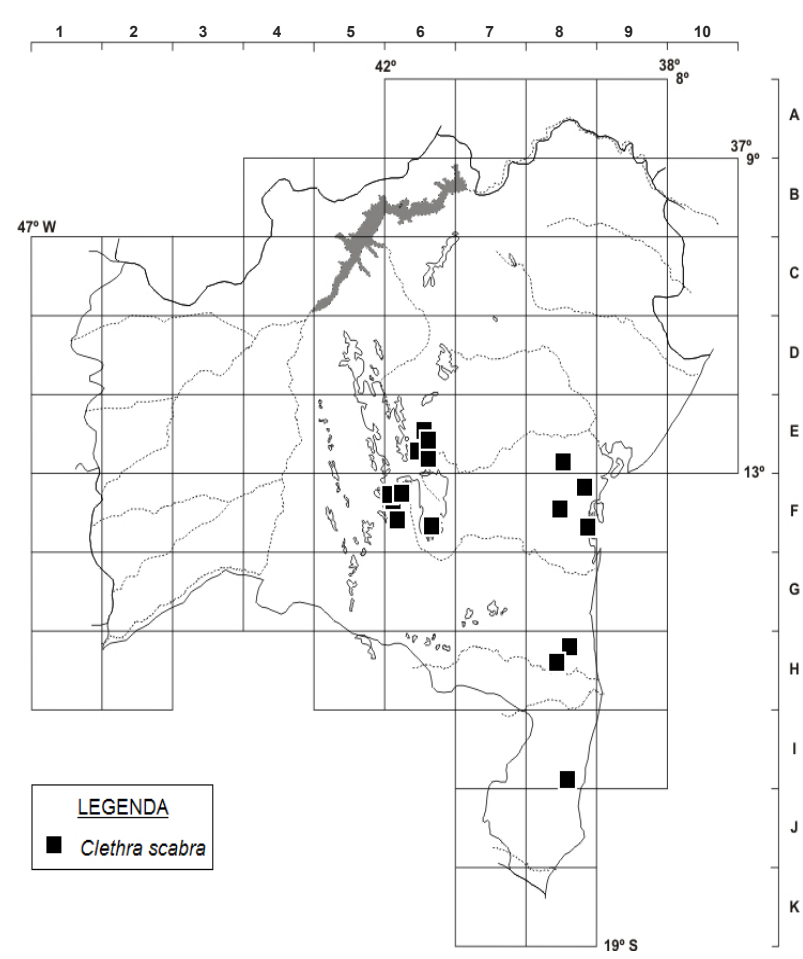

Figura 1. Distribuição geográfica de Clethra scabra no estado da Bahia.

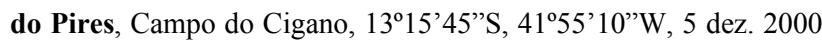
(fl., fr.), F.H.F. Nascimento 403 (HUEFS); Santa Terezinha, Serra da Jiboia, 12'52'10'S, 39²8'18”'W, 1 dez. 2004 (fr.), M.L.C. Neves et al. 179 (HUEFS); Tancredo Neves, estrada para os distritos de Água Branca e Julião, ca. 14,1 km de Tancredo Neves, 13²6'36"S, 39³0'40”W, 554 m s.n.m., 11 dez. 2005 (bot.), A.M. Amorim et al. 5473 (CEPEC).

As variedades de Clethra scabra citadas para o estado da Bahia (Guimarães et al. 2015), C. scabra var. laevigata e C. scabra var. scabra, são normalmente diferenciadas com base em caracteres foliares. Clethra scabra var. scabra apresenta folhas subcoriáceas a coriáceas, com face abaxial tomentoso-ferrugínea, enquanto $C$. scabra var. laevigata apresenta folhas papiráceas, com face abaxial tomentosa e cinéreoalvacenta (Ichaso \& Guimarães 1975). A maioria dos indivíduos que ocorre nas montanhas da Chapada Diamantina apresenta lâminas foliares mais rígidas e coriáceas, enquanto os indivíduos que ocorrem ao longo da Mata Atlântica apresentam geralmente lâminas mais papiráceas. Entretanto, alguns indivíduos não se encaixam neste padrão e há uma grande sobreposição em relação ao indumento foliar. Sendo assim, as variedades de Clethra scabra não foram reconhecidas aqui.

\section{AgRAdecimentos}

Aos curadores dos herbários ALCB, ASE, CEPEC, HRB, HUEFS, pelo acesso às coleções. Ao CNPq e à FAPESB, pelo financiamento dos projetos de apoio à 


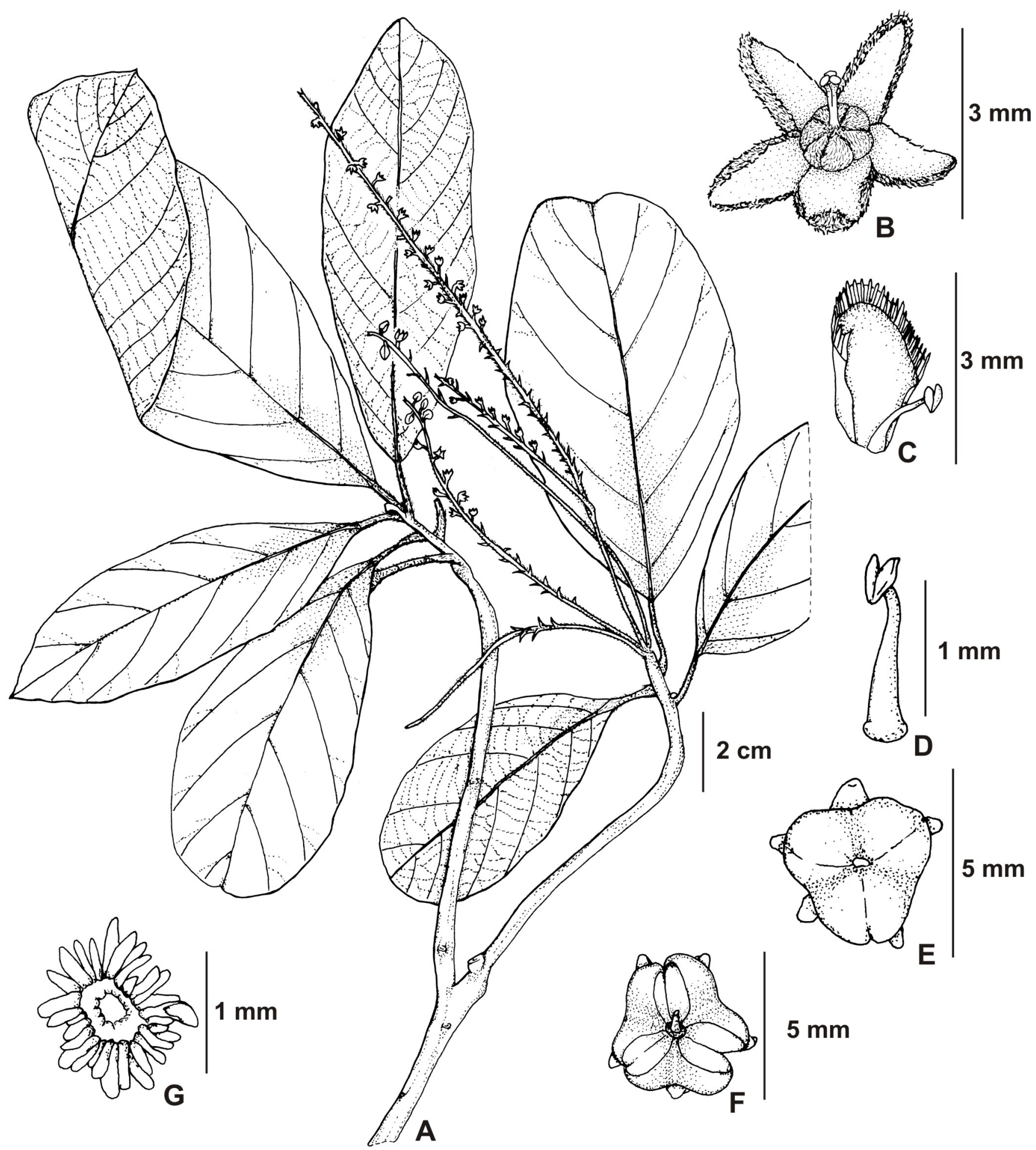

Figura 2. Clethra scabra: A- ramo com flores; B- flor; C- pétala com estame adnato; D- estame; E- fruto; F- fruto aberto; G- semente alada. (A-D- Cardoso 1585; E-G- Paixão 955).

Flora da Bahia FAPESB APR 162/2007 e CNPq processos 562278/2010-9 e 483909/2012. Ao CNPq, pela bolsa de mestrado concedida ao primeiro autor (processo 131311/2009-3/GM). AMG e RPO agradecem ao $\mathrm{CNPq}$ pela bolsa de Produtividade em Pesquisa (PQ Sênior e PQ1-D, respectivamente); ao Thiago Araújo pela ilustração; e ao Lucas Marinho pela finalização em nanquim da ilustração.

\section{REFERÊNCIAS}

APG III 2009. An update of the Angiosperm Phylogeny Group classification for the orders and families of flowering plants: APG III. Botanical Journal of the Linnean Society 161: 105-121.

Fior, S.; Karis, P.O. \& Anderberg, A.A. 2003. Phylogeny, taxonomy, and systematic position of Clethra (Clethraceae, Ericales) with notes on biogeography: evidence from plastid and 
nuclear DNA sequences. International Journal of Plant Sciences 164(6): 997-1006.

Guimarães, E.F.; Medeiros, E.S. \& Romão, G.O. 2015. Clethraceae. In: Lista de Espécies da Flora do Brasil. Instituto de Pesquisas Jardim Botânico do Rio de Janeiro. Disponível em http://floradobrasil.jbrj.gov.br/jabot/floradobrasil/FB88; acesso em mar. 2015.

Gustafsson, C. 2004. Clethracae. In: N. Smith, S.A. Mori, A. Henderson, D.W. Stevenson \& S.V. Heald (eds), Flowering Plants of the Neotropics. Princeton University Press, Princeton, p. 104-105.

Ichaso, C.L.F. \& Guimarães, E.F. 1975. Cletráceas. In: R. Reitz (ed.), Flora Ilustrada Catarinense. Herbário Barbosa Rodrigues, Itajaí, p. 1-19.
Rossi, L. 1992. Clethraceae. In: M.M.R.F. Melo, F. Barros, S.A.C. Chiea, M.G.L. Wanderley, S.L. Jung-Mendaçolli \& M. Kirizawa (eds), Flora Fanerogâmica da Ilha do Cardoso (São Paulo, Brasil). Vol. 3. Instituto de Botânica, São Paulo, p. 69-71.

Schneider, J.V. \& Bayer, C. 2004. Clethraceae. In: K. Kubitzki (ed.), The Families and Genera of Vascular Plants. Flowering Plants, Dicotyledons: Celastrales, Oxalidales, Rosales, Cornales, Ericales. Vol. VI. Springer-Verlag, Berlin, p. 69-73.

Sleumer, H. 1967. Monographia Clethracearum. Botanische Jahrbücher für Systematik, Pflanzengeschichte und Pflanzengeographie 87: 36-175.

\section{LISTA DE EXSICATAS}

Amorim, A.M. 5473; Bautista, H.P. 3583; Borges, R.A.X. 661; Cardoso, D. 1585; Carvalho, A.M. 960; Carvalho-Sobrinho, J.G. 189; Conceição, A.A. 1197, 1316; França, F. 1000; Ganev, W. 1470, 2459, 2641; Guedes, M.L. 1479, 6938, 11464; Harley, R. 15686, 17861, 18115, 27843; Jardim, J.G. 2852; Melo, E. 1723; Nascimento, F.H.F. 123, 403; Neves, M.L.C. 179; Paixão, J.L. 955, 1090; RibeiroFilho, A.A. 175; Smidt, E.C. 215; Stradmann, M.T.S. 90. 